\title{
Curriculum, program, and infrastructure development for Bachelor of Science in Optical Science and Engineering
}

Marek Osiński, Sudhakar Prasad, Arthur Guenther, Anne Madsen, Christine McCormick

Marek Osiński, Sudhakar Prasad, Arthur H. Guenther, Anne L. Madsen, Christine B. McCormick, "Curriculum, program, and infrastructure development for Bachelor of Science in Optical Science and Engineering," Proc. SPIE 9663, Eighth International Topical Meeting on Education and Training in Optics and Photonics, $96631 \mathrm{~T}$ (6 October 2003); doi: 10.1117/12.2207507

Event: Eighth International Topical Meeting on Education and Training in Optics and Photonics, 2003, Tucson, Arizona, United States 


\title{
Curriculum, program, and infrastructure development for Bachelor of Science in Optical Science and Engineering
}

\author{
Marek Osiński \\ Department of Electrical and Computer Engineering, University of New Mexico, Albuquerque, New Mexico 87131 \\ Telephone+1505272-7812; Fax+1505272-7801; E-mail: osinski@chtm.unm.edu \\ Sudhakar Prasad \\ Department of Physics and Astronomy, University of New Mexico, Albuquerque, New Mexico 87131
}

Arthur H. Guenther

Center for High Technology Materials, University of New Mexico, Albuquerque, New Mexico 87106-4343

Anne L. Madsen

Department of Educational Specialties, University of New Mexico, Albuquerque, New Mexico 87131

\author{
Christine B. McCormick \\ Department of Individual, Family, and Community Education, University of New Mexico, Albuquerque, New Mexico 87131
}

\begin{abstract}
University of New Mexico has developed a comprehensive plan for a new B.S. degree in Optical Science and Engineering, accompanied by teacher training and enhancement of K-12 optics education. The plan incorporates curriculum development, creation of new laboratories, development of optics courses for teachers, creation of outreach programs, and involvement of industry and government laboratories.

(C)2003 Optical Society of America

OCIS codes: $(000.2060)$ Education
\end{abstract}

\section{Introduction}

Over the last year, the faculty of the Department of Electrical and Computer Engineering (EECE) in the School of Engineering, the Department of Physics and Astronomy in the College of Arts and Sciences, the Department of Educational Specialties in the College of Education, and the Department of Individual, Family, and Community Education in the College of Education at the University of New Mexico (UNM) have jointly developed a comprehensive plan for a new B.S. degree in Optical Science and Engineering (OSE), with emphasis on education in the field of photonics, accompanied by teacher training and enhancement of K-12 optics education initially at the high- and middle-school levels, and eventually reaching down to the elementary school level in the implementation stage of this program. Specifically, the plan incorporates development of a new college degree curriculum, creation of new laboratories, development of courses training K-12 teachers in optical science and engineering, creation of outreach programs, identification and activation of sources of support for minority students, and involvement of local and national industry and government laboratories.

Through the incorporation of current pedagogical learning theories concerning instructional design and assessment, the new degree curriculum will support a new model that will be available for use by other engineering programs at UNM's School of Engineering and nationwide. Most importantly, the new degree will bridge the last remaining gap in the unique hierarchy of photonics educational programs in New Mexico, starting with the Photonics Academy at West Mesa High School supported by the Sandia National Laboratories that feeds into the Photonics Technology Associate Degree program at the Albuquerque Technical Vocational Institute, and ending with the M.S. and Ph.D. programs in Optical Science and Engineering offered at UNM. The comprehensive line-up of educational and career options in optics and photonics that would be enabled by the planned B.S. degree will permit New Mexico industry to fill its photonics-centered positions at all levels, from the technician to the advanced researcher, from a workforce trained locally. The planned degree will, more generally, help meet the emerging workforce and educational needs of the entire US industry.

There is critical need for a new approach in undergraduate engineering education, and this is particularly true for a cross-disciplinary field like optical science and engineering. A major emphasis in the planning process is placed on enhancement of the quality of learning that can result from collaborative interactions between the optics and 
education faculty. These are expected to create conditions in which cognitive science research will be actively conducted and applied to optics and photonics education. We further expect that this unique environment will result in the creation of the first normative model of optics and photonics professional education.

\section{Rationale for developing a B.S. degree program in Optical Science and Engineering at UNM}

\subsection{Background}

We live in a world bathed in light. We see with light, plants draw energy from light, and light is at the core of technologies from computing to surgical techniques. The field of optics concerns exploiting light to perform useful tasks.

A recent study by the Committee on Optical Science and Engineering of the National Academies of Science and Engineering entitled, "Harnessing Light, Optical Science and Engineering for the Twenty-First Century", surveys the impending explosive growth of optics and its allied field of photonics and their unrivalled position as the next major technology to drive the economy and improve our quality of life.

The report has convincingly documented that optics is pervasive, impacting the fields of biomedicine, information technology, defense, manufacturing, energy and the environment, as well as supporting educational research activities. Light influences our lives today in new ways that we could never have imagined just a few decades ago. In the 21 st century, light will play an even more significant role, enabling a revolution in worldwide fiber-optic communications, new modalities in the practice of medicine, a more effective national defense, exploration of the frontiers of science, and much more.

We are beginning to see the fruits of the scientific discoveries of the last three or four decades. The development of the laser in the 1960s produced intense light with a property never seen before on Earth: coherence. Coherent light can be directed, focused, and propagated in new ways that are impossible for incoherent light. This property of laser light has made possible fiber-optic communications, compact disks, laser surgery, and a host of other applications that add up to a multitrillion-dollar worldwide market. Applications of incoherent light abound as well, including optical lithography systems for patterning computer chips, high-resolution microscopes, adaptive optics for Earth-based astronomy, infrared sensors for everything from remote controls to night-vision equipment, and new high-efficiency lighting sources.

Although optics is pervasive in modern life, it is sometimes viewed as an orphan discipline because its power is predominantly realized in the enabling of other fields. For example, a \$1B investment in photolithography gives birth to a $\$ 300 \mathrm{~B}$ semiconductor market. Additionally, the growth of the fiber optics industry with fibers being laid continuously at the speed of a Mach 2 aircraft, about $1400 \mathrm{mph}$, empowers the information highway and fuels the burgeoning telecommunications market. Daily, in the media, we see its utility in defense, ranging from precisionguided munitions to enabling our troops to "own the night" through the use of infrared viewing devices. Traditional reconnaissance cameras are now being digitized and displayed optically. Optics and photonics are truly ubiquitous. As an ever-greater variety of commercial optical products are manufactured, the need for scientists and engineers with a broad optics education continues to rise.

While optics is essential, it typically plays a supporting role in a larger system. Central issues for this field include the following:

- How to support and strengthen a field such as optics whose value is primarily as an enabler?

- How to ensure the future vitality of a field that lacks a recognized, traditional academic or disciplinary home? Optics and photonics promise to be as important in the future as electronics and computers have been in the past. They form one of the most important technology clusters identified by the Next Generation Economic Initiative (NGEI) for the state of New Mexico, and they greatly enhance the other clusters in biomedical, information technology, electronics and microsystems (nanoscience). New Mexico has long been a world leader in optical technologies and the industry is thriving with new and expanding companies. Photonics will support the further development of Kirtland Air Force Base in the directed energy arena (e.g. lasers, etc.) and in its growing role as the tri-service Department of Defense prime R\&D center. It is worth pointing out that the NGEI initiative has amalgamated and is stimulating further growth of already burgeoning New-Mexico-based industrial and educational establishments in optics.

\subsection{Existing local strengths}

As indicated earlier, the proposed B.S. degree program will fill the last educational niche in optical science and engineering and respond to increasing local workforce needs for qualified technicians, engineers and scientists. It 
will be greatly assisted and complemented by important resources and time-honored programs that are already in place. The most important of these unique resources are the following:

- Photonics Academy - In the late 1990s, a new need began to emerge on the Albuquerque horizon. It revolved around Sandia's Microsystems Initiative and the associated concern of where the technicians providing the bulk of the workforce would come from to serve this optics-enabled field. Based upon the already proven success of the Manufacturing Academy at West Mesa High School developed in the mid to late 1990s, a request for proposal was initiated by Sandia. West Mesa High School was again selected and a Photonics Academy was created, that formally articulates between West Mesa High School and ATVI. Initially, $\sim 25$ students participated in the fledgling Photonics Academy program. The ${ }^{\text {th }}$ grade enrollment for the academic year 2002/2003 increased by $100 \%$ over the previous year, attesting to the tremendous success of the program. The most recent recruitment for the year 2003/2004 resulted in 90 applications, out of which 70 new students have been admitted to the Academy. To ensure that students coming into West Mesa are prepared for the optics academy, extensive recruiting and information sessions are held in the middle schools that feed West Mesa. Based upon its successful experience in the manufacturing area, Sandia plans to offer internships upon graduation from West Mesa High School to as many as 8-10 students/year as they continue their education. Apart from the invaluable service to the optics industry this program is likely to provide, Sandia is also in this way growing its own microsystems staff.

The impact of this program is not limited to the vertically upward direction. To make students and parents aware of career opportunities, West Mesa High School plans to go to its feeder middle schools and introduce students to careers in optics and photonics. These informational meetings will help students "see the light" in an exciting and illuminating career in optics and photonics.

- AAS in Photonics Technology - This program, housed at Albuquerque Technical Vocational Institute (ATVI) and approved by the New Mexico Commission for Higher Education in August 2001, offers a oneyear certificate and two-year Associate of Applied Science degree in Photonics Technology. The program has been extremely successful with bursting enrollment, and the class size had to be doubled to accommodate a strong demand among the students. The program started with 8 students in September 2001. To date, 20 students have declared they will pursue the certificate option, while 16 have chosen the AAS degree path. At present, 62 students are taking photonics-related courses at ATVI. Since this program could feed directly into the new B.S. program, its early success clearly demonstrates the need for photonics education at all levels [Navarra 2001]. It also shows that the scope and impact of the West Mesa High School Academy can be successfully broadened to include a higher-education career pathway that will open up further employment and professional development opportunities for students.

- M.S. in Optical Science and Engineering - A new M.S. degree program in Optical Science and Engineering, emphasizing partnership with NM Optics Industry Association (NMOIA) and the national laboratories of New Mexico, was introduced in the Fall 2002 semester. Building upon and down from the Ph.D. program in Optical Sciences, the M.S. program is designed to help meet the growing need for shorter-term specialized training in a technical area that is critical to the economy of New Mexico. This M.S. degree program was established in direct response to a strong need expressed by NMOIA. Students of this degree program will be able to pursue an Industrial Internship either at an optics industry or at a national laboratory in NM, and thus to develop first-hand appreciation for the challenges of an industrial career. The industry similarly will have a first-hand look at prospective employees and be able to train them, before they formally graduate, for a career that will serve them well. This close cooperation between UNM and the photonics industry under the M.S. program will foster a synergistic environment in which UNM can contribute to an education that has an immediate and readily measurable impact on the economy of the state and the country.

- Ph.D. in Optical Science and Engineering - UNM has long been a leader in graduate optics education with an interdisciplinary focus. The Ph.D. program in Optical Sciences (renamed Ph.D. in Optical Science and Engineering in Spring 2003) dates back to 1983, when the departments of Physics and Astronomy (P\&A) and EECE jointly recognized a growing early need for a broad-based graduate program that covered the gamut from optical science to engineering in its overall emphasis. This program has already produced over 75 graduates who have gone on to diverse careers in industry, academia, and government laboratories statewide, nationally, and internationally. The program anticipated the need for cross-disciplinary emphasis in optics education and research that would not be widely recognized for another decade or so.

- NSF/IGERT Program in Optics- A Cross-disciplinary Optics Research and Education (CORE) grant involving the departments of Biology, Chemistry, Chemical Engineering, EECE, and P\&A was recently funded at UNM under the NSF/IGERT program to enhance the education and training of graduate students. 


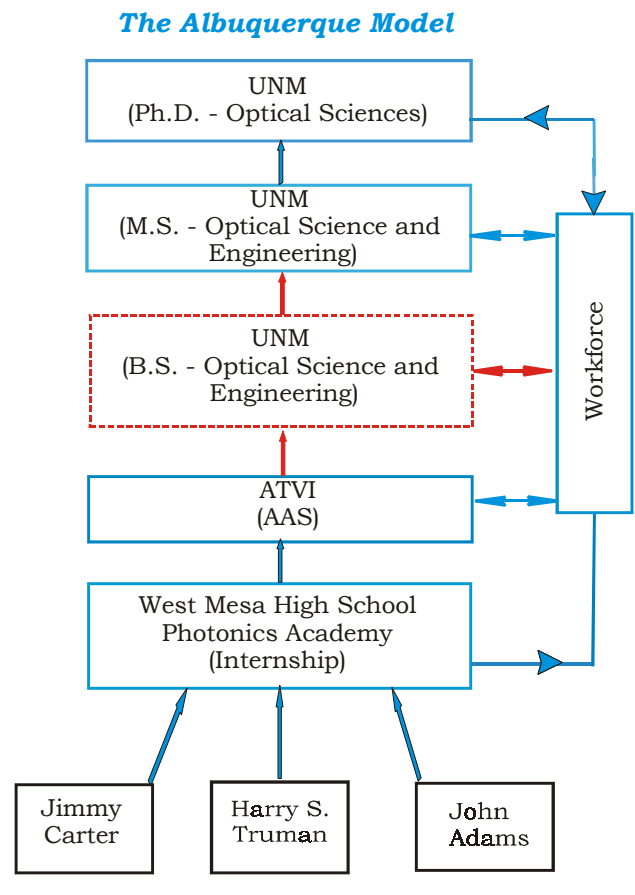

Middle Schools

Fig. 1. Education ladder for careers in optics and photonics - present status.
The research and educational theme of the CORE project is centered on optical imaging and spectroscopic techniques with high spatial and temporal resolution and their application to physical, chemical, and biological problems. In addition to the current curricula in their respective departments, IGERT students take a set of cross-disciplinary courses designed specifically for the program. The IGERT fellows will be offered internships in the local optics industry, in national laboratories, and abroad to widen their horizons and to introduce career opportunities. A weekly seminar series will provide the students with training in technical writing and in presentations of their research in a multi-disciplinary environment. An important emphasis of the CORE program is on mentoring of undergraduate students by the CORE students, to help foster team spirit and leadership skills and to recruit, retain, and involve undergraduates, in particular those from underrepresented minorities, in research. Students enrolled in the new optics B.S. degree will be able to benefit from such mentoring.

Each of the educational initiatives described above was taken independently to solve a specific organization's need. But they have all come together beautifully, in an almost seamless manner, to create, to a large degree, a well articulated educational ladder from which students can exit and enter the workforce at different rungs, based on their needs, ability, interest, and employment opportunities. This education ladder in its entirety is unique and places New Mexico in a leading position in the nation. As illustrated in Fig. 1, the new B.S. in Optical Science and Engineering degree is the last remaining rung that needs to be added to this ladder to make it complete.

\section{Improved pedagogy in undergraduate optical science and engineering}

There is critical need for a new approach in undergraduate engineering education, and this is particularly true for a cross-disciplinary field like optical science and engineering. Though the basic laws of nature have not changed, there has been an extensive change in how engineers apply them to meet the needs of society, both in terms of the tools they use and the projects they work on. Likewise, there has been an enormous change in the understanding and application of pedagogy in engineering education as well as in the technology available to deliver it. It is essential that engineering education make use of the best available techniques for designing and delivering content appropriate for the $21^{\text {st }}$ century.

A major emphasis in the new program will be placed on enhancement of the quality of learning that can result from collaborative interactions between the optics and education faculty. The approach towards improved pedagogy in this program will be based on a set of assumptions about human learning and educational design that is consistent with the National Research Council's "How People Learn" framework [Bransford 1999], which takes the form of four overlapping lenses that can be used to analyze any learning situation. In particular, research on how people learn suggests that we ask about the degree to which learning environments are:

- knowledge-centered in the sense of being based on a careful analysis of what we want people to know and be able to do when they finish with the teaching materials or course, as well as providing learners with the foundational knowledge, skills and attitudes needed for successful transfer;

- learner-centered in the sense of connecting to the strengths, interests, and preconceptions of learners, and helping them learn about themselves as learners;

- assessment-centered in the sense of providing multiple opportunities to make students' thinking visible so they can receive feedback and be given chances to revise their thinking in continual manner; and

- community-centered in the sense of providing an environment - both within and outside the classroom where students feel safe to ask questions, learn to use technology to access resources, work collaboratively, and are helped to develop lifelong learning skills.

In order to create such a learning environment at the global level of the bachelor's degree, we will follow a systematic instructional design process undertaken by all stake holders that includes the discrete steps of: 
- learner and task analysis;

- articulation of instructional objectives;

- description of courses based on the identified instructional objectives; and

- both formative and summative evaluation of the program design and development process.

Such a systematic design process involving all the interested parties will promote two critical outcomes: a clearer understanding of the target audience in both cultural and educational terms, and an alignment between the various constituent educational programs. We believe that such a systematic process for the development of a new degree program represents a significant departure from a typical approach taken in the past.

As discussed in more detail in Section 3.2, there is an ample body of evidence to suggest that active learning techniques leave students with a greater level of knowledge, better learning skills, and a higher rate of knowledge retention when compared with students exposed to other forms of learning. In a traditional lecture course setting, medical students' attention was reported to be high only during the first 10 to 15 minutes and then to decline abruptly [Stuart 1978], [Penner 1984]. Hammen and Kelland concluded that very little learning occurred during lectures, when they showed only a weak correlation between lecture attendance and course grades in medical school courses [Hammen 1994]. These studies, however, focused on medical students, and to what extent they apply to other disciplines is arguable. To our best knowledge, no such studies have been reported yet in the case of optical science and engineering students. Which particular courses will benefit from active learning methods, and which courses will be more effective in their traditional setting, awaits further research. Close interactions between the optics and education faculties envisaged in the new program are expected to create conditions in which cognitive science research will be actively conducted and applied to optics and photonics education. We further expect that this unique environment will result in the creation of the first normative model of optics and photonics professional education.

On the level of individual course design, the faculty participating as designers of instruction will follow a "working backwards" strategy as articulated in Understanding by Design [Wiggins 1998]. This instructional design model incorporates specific strategies for achieving the research-based learning environment outlined by the National Research Council framework referenced above. Understanding by Design also addresses the concepts of constructivist, inquiry-based learning as a critical attribute for achieving meaningful understanding in learners as the foundation for functional competence in real world settings. As college faculty are assigned teaching responsibilities with little if any training in the systematic design of instruction, this, too, represents a significant improvement over the norm and is likely to support increased instructional effectiveness.

\subsection{Freshman program}

Throughout the USA, a dangerous trend toward shrinking engineering enrollments, noted already in the early nineties, poses a potentially serious problem for American industry and society. The annual engineering graduation rate has decreased by roughly $20 \%$ in the last decade, while the number of engineering jobs has risen by $\sim 25-30 \%$ [Felder 1998]. The decline in the graduation rate can be attributed to both the increasing difficulty of attracting high school graduates into engineering and high attrition rates of enrolled engineering students. Most engineering schools have undertaken major recruitment efforts to address the first problem, targeting especially women and minorities. However, since freshman enrollment is heavily influenced by factors out of the university's control, these efforts have a limited potential for success [Heckel 1996]. A much more effective way to improve graduation rates is therefore to develop methods for improved retention of engineering freshmen.

Considering the strong academic records of most students who choose to go into engineering, high rates of attrition are truly alarming. A monumental study of nearly 25,000 students at over 300 institutions established that only $43 \%$ of the engineering freshmen went on to graduate in engineering [Astin 1993]. Similar results were obtained in a more limited study of 1,151 engineering freshmen at Iowa State University [Moller-Wong 1997]. After five years, $32 \%$ of the cohort graduated in engineering and $13 \%$ were still enrolled, for a probable eventual graduation rate between $40 \%$ and $45 \%$.

With these statistics at hand, the issue of retention must lie at the heart of any new engineering program. A frequently encountered explanation of high engineering-student attrition rates is that most of those who leave lack the academic ability to cope with the rigors of the discipline. However, studies have shown that this interpretation is incorrect, with little difference in academic performance between students that choose to stay in engineering and those that choose to leave [Besterfield-Sacre 1997]. The true explanation appears to involve a complex set of factors, including students' attitudes toward engineering, their self-confidence levels, and the quality of their interactions with instructors and peers, along with their aptitude for engineering. 
The present structure of freshman engineering curricula at UNM has very little engineering content, which essentially reduces the engineering degree programs to three years, with the first-year's filter focusing on prerequisites in calculus, physics, and chemistry. We plan to utilize the positive experience of NSF-funded Engineering Education Coalitions (EECs), where even the first-year students learn engineering within a connected intellectual and social context. Significantly improved retention among students who elect to take the first-year engineering courses at the universities participating in the EECs [Felder 1998] shows that early offering of subjectoriented courses is very effective in building community and social support that are vital as students go through a challenging curriculum. This is consistent with earlier findings that students' attitudes toward engineering and their confidence levels were strongly related to their classroom experience [Astin 1993]. Compared to majors in other fields, engineering majors were much more dissatisfied with the quality of instruction they received in college and with their overall college experience. Apart from course content, the prevalent model of instruction in engineering, with its extensive reliance on lecturing and individual work and norm-referenced grading (curving), played a major role in this high dissatisfaction level and therefore in student attrition. Many educational scholars have since recommended establishing an alternative instructional environment in engineering curricula that includes the use of active and cooperative learning tools and a variety of other pedagogical methods designed to accommodate different learning styles [Astin 1993], [Meyers 1993], [McKeachie 1994].

Based on these data, we are developing an innovative first-year optical science and engineering curriculum incorporating the following pedagogical theories of the Foundation Coalition:

- Active/Collaborative Learning

- Student Teams in Engineering

- Increasing Participation of Women and Underrepresented Minorities in Engineering

- Curriculum Integration

- Continuous Improvement through Assessment, Evaluation, and Feedback

- Technology-Enabled Learning

- Curricular Change, Resistance, and Leadership

We are designing first-year courses with optics and photonics-based real-life project content, where students will be working and learning in teams. This will help them confront the difficulties they may encounter, as well as learn about the advantages of participating in a team effort. They will learn why optical scientists and engineers need to learn physics, mathematics, chemistry, ethics, economics, and social implications of technology, and they will make better connections between these subjects and the practice of engineering.

\subsection{Active and cooperative learning}

Research has shown consistently that traditional lecture methods, in which professors talk and students listen, dominate college and university classrooms [King 1993]. According to a study published in 1987, 89\% of U.S. physics and mathematics professors lectured as a mode of instruction [Thielens 1987]. The greatest advantage of lectures in the opinion of teaching faculty is the ability to share information with a large number of students [Gage 1998]. However, a vast body of literature shows that students must do more than just listen to truly learn [Craik 1972], [Poppenhagen 1982], [Chickering 1987], [Bolles 1988], [Sutherland 1996]. A schematic illustration of this statement is represented in now classic "cone of experience", shown in Fig. 2.

In active learning, students are engaged in various activities beyond just listening. They are involved in dialog, debate, writing, and problem solving, as well as higher-order thinking, e.g., analysis, synthesis, and evaluation [Bonwell 1991]. Use of these techniques in the classroom is vital because of their powerful impact upon students' learning. For example, several studies have shown that students prefer strategies promoting active learning to traditional lecture. Furthermore, some cognitive research has shown that a significant number of students have learning and cognitive styles best served by pedagogical techniques other than lecturing. On the other hand, it should be noted that the connection between student preferences and actual performance when provided with their preferred method of learning has not been well-established and requires further research [Jonassen 1993].

Classroom discussion is preferable to lectures if the objectives are to promote long-term retention of information, to motivate students toward further learning, to allow students to apply information in new settings, and to develop students' thinking and analytical skills [McKeachie 1986]. However, in order to achieve these goals faculty must be knowledgeable about alternative techniques and strategies for questioning and discussion [Hyman 1980] and must create a supportive intellectual and emotional environment that encourages students to take risks [Lowman 1984]. Hence, proper preparation of teaching faculty through workshops will be necessary. Further discussion of the need for faculty workshops and its planned implementation is presented in Section 3.6. 


\section{CONE OF LEARNING}

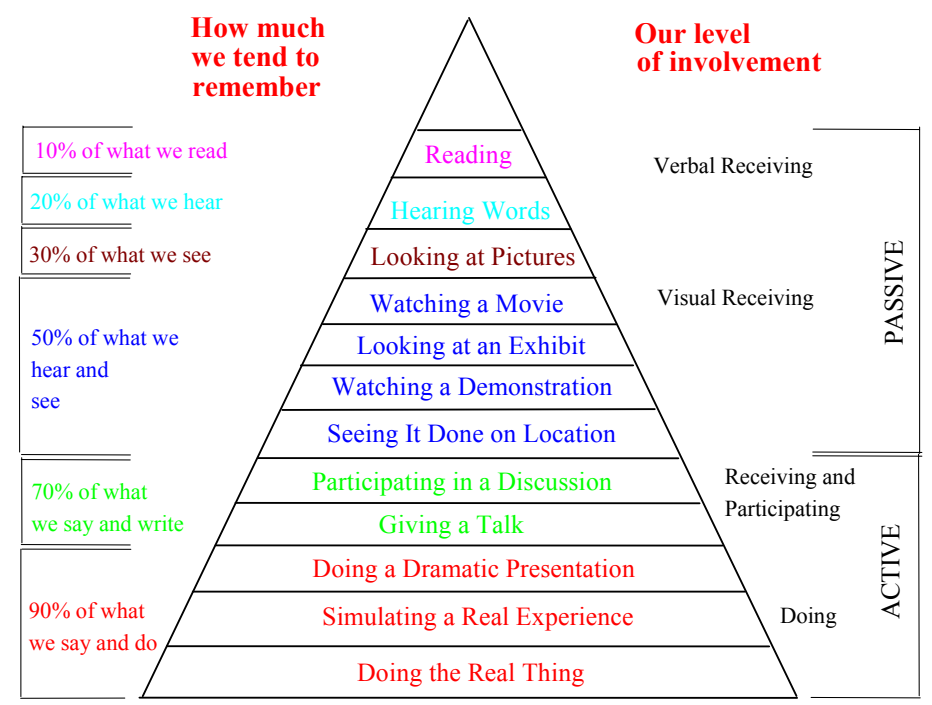

Fig. 2. Edgar Dale's "Cone of Learning", illustrating how effectiveness of teaching improves with an increased student participation. After: The Foundation Coalition, http://www.foundationcoalition.org

The published literature on alternatives to traditional classroom presentations provides a rich menu of different approaches faculty can readily add to their repertoire of instructional skills. Specific techniques that will be considered in order to incorporate active learning in the new optical science and engineering curriculum include:

- simple modifications of traditional lectures, for example, a faculty member allowing students to compare their notes by pausing three times for two minutes each during a lecture [Ruhl 1987], brief hands-on experiments or demonstrations in which students participate directly [Kvam 2000], lecturing by questioning (the Socratic method) [King 1993], or short, ungraded writing exercises followed by class discussion;

- feedback lecture, which consists of two minilectures separated by a small-group study session built around a study guide;

- guided lecture, in which students listen to a 20- to 30-minute presentation without taking notes, followed by their writing for five minutes what they remember and spending the remainder of the class period in small groups clarifying and elaborating the material;

- visual-based instruction, especially important in the context of distance education (see Section 3.5) which can also provide a helpful focal point for other interactive techniques;

- in-class writing across the disciplines is another productive way to involve students in doing things and thinking about the things they are doing;

- experiential or activity-based learning [Gage 1998];

- problem-solving instructional strategies which include the case study method of instruction and Guided Design;

- interactive computer-based learning [Burden 1998]; and

- focused interactive learning based on principles of dynamic social impact theory [Latane 2002].

Cooperative learning is the instructional use of small groups in which students work together to maximize their own and each other's learning. If instituted properly, it can produce higher achievement, more positive relationships among students, and healthier psychological adjustment than do competitive or individualistic experiences. Five essential components must be present for small-group learning to be truly cooperative [Johnson 1991]:

- clear positive interdependence between students;

- face to face interaction;

- individual accountability;

- emphasis on interpersonal and small-group skills;

- processes in place for group review to improve effectiveness.

Among various cooperative learning methods, we will explore whole class and group discussions [Gage 1998], peer teaching and collaborative group learning, and role-playing or simulations [Burden 1998], as well as informal cooperative strategies such as Think-Pair Share [Johnson 1991]. In particular, we note that students working in small 
groups in engineering laboratory courses were more likely to be able to generalize from specific observations, were superior at applying concepts to new situations, and had a greater ability to critically analyze what they read and synthesize information from a variety of sources [Collier 1980]. In general, students working in groups appeared to have increases in the attributes of self-directed learning and in obtaining relevant help for facilitating learning when compared with students in lecture-only courses [Poppenhagen 1982].

According to [Bonwell 1991], previous classroom initiatives and written materials about active learning have been too isolated and fragmented. The resulting pedagogical efforts have therefore lacked coherence, and the goal of interactive classrooms has remained unfulfilled. To a large extent, these statements are still true, especially when applied to UNM's undergraduate instruction in engineering. We believe that the Bridges for Engineering Education framework adopted for the new degree program offers a unique opportunity for a coordinated efforts of optics faculty, educational researchers, and academic administrators, to make real the promise of active and cooperative learning.

\subsection{Curriculum integration}

The new curriculum will include elements of many disciplines, utilizing the ubiquity of optics as enabling technology in various fields, as well as its relation to the economy, manufacturing, ethics, and similar disciplines. A good example to follow has been recently set by the Department of Civil and Environmental Engineering at the United States Air Force Academy, where a capstone senior level integration course was developed [Jenkins 2002]. The course blends technical aspects of engineering design with construction and realistic issues of modern society. Technical designs accomplished by the students prior to taking the capstone course form the basis of the capstone design experience. The students review the technical design and prepare the project for construction through incorporating engineering standards and considering realistic issues, such as economics, constructability, and environmental aspects, as well as ethical, health and safety constraints. The students prepare a final design report and make an oral presentation to an interdisciplinary panel of engineering faculty. This capstone course is the culmination of a total integration experience, which includes a hands-on field engineering course, and two years of a rigorous engineering design curriculum.

\subsection{Integration of research and education}

The involvement of undergraduate and graduate students in research is an important and powerful educational tool. In a research setting, technical discussions between students and senior investigators, or among students, expose the student to knowledge that goes well beyond the material covered in the classroom. This allows the student to "try out" ideas that have been learnt in class and to contribute to the generation of new knowledge. In addition, the research environment provides the student with an important opportunity for professional development through interactions at conferences, meetings with program managers, and internships in government laboratories or industry. The skills of communication and networking that are learnt during these interactions are vital for today's graduates.

The new program will benefit from the existing vibrant research in optical science and engineering conducted in both EECE and Physics \& Astronomy Departments as well as in the Center for High Technology Materials, with its strong focus on photonics and sensors - areas important to homeland defense. A graduate mentorship program will be established, whereby undergraduate students will be working on research projects in a team environment, under direct supervision of graduate students. In addition, students enrolled in this program will be able to participate in UNM's Co-op program, placing them in local industry or in national laboratories for summer internships. Both these mentorship and internship programs will greatly benefit form a similar methodology adopted for integration of graduate research, education, and training under the just begun NSF/IGERT cross-disciplinary project CORE (see Section 2.2) that stresses the role of optics in physics, biology, chemistry, and electrical engineering applications.

In addition to research experience in optics and photonic, the new program will provide research opportunities for education students who will be able to conduct research on novel teaching and assessment methods as they become implemented in this program.

\subsection{Distance education}

Distance education is an important instructional tool well suited to overcoming barriers of time and space. It is an effective means of facilitating learning, especially useful for reaching those unable to attend conventional university classes due to time or geographic constraints. The new program will aim at increasing the number of web-based and ITV course offerings, especially at the lower-end (first two years) of the curriculum. 
Development of an undergraduate curriculum with a strong distance learning component is particularly important for the University of New Mexico with its branch campuses in Gallup, Valencia, Los Alamos, and Taos, extending as far as 150 miles away from its main campus in Albuquerque. In addition, UNM operates distance learning sites in Farmington and Zuni, as well as the two Diné College sites in Shiprock and Crownpoint. All of these sites either expect to have or already have 'smart classrooms' in place to teach distance education courses. Several are also hooked up to the access grid at the Albuquerque High Performance Computing Center, so that multiple sites can be rapidly reflected on the same projector screen.

\subsubsection{Web-based teaching}

Web-based teaching, a rapidly evolving form of technology-enabled learning, represents a tremendous opportunity for pedagogical development, and will be explored in depth for enhancing the new curriculum. The asynchronous nature of a web-course allows the student to pursue it in a convenient time setting. This flexibility empowers students, and can result in a more active and mature participation in the course.

The objective of most engineering courses is to enable each student to understand and learn a common body of knowledge. In a well-designed web-course this can be achieved by allowing different students to follow different paths to a common endpoint. This constructivist or "adaptive" approach requires more upfront time in designing the course, but the pay-off in learning gains can be significant.

Online bulletin boards provide students with another asynchronous (and therefore time flexible) forum for discussions amongst themselves and with the instructor. These interactions can foster a truly cooperative learning environment in which students answer each other's questions and guide each other through problem areas.

With conventional learning, the student must adapt to either the classroom instructor's individual teaching style, or the predefined format of the distance-learning program. Recent demonstration at Lehigh University of the world's first web-enabled adaptive learning technology developed by Invensys PLC opens up a new avenue for courses that can accommodate individual student's learning styles to maximize teaching effectiveness. This technology can be utilized to create both face-to-face classroom programs and remote learning programs that are customized to each student's preferences. The adaptive learning technology uses a web-enabled "Learning Style Inventory", which assesses a student's individual learning style and then adapts the specific course material. More than 80 different learning traits have been identified and are incorporated in the inventory and resulting course material created for each student. We intend to contact Invensys to explore possibilities of purchasing their technology for use at UNM.

While we believe that these new tools will allow us to significantly improve the effectiveness of our new curriculum and make the learning process more enjoyable both for students and teachers, we are aware that they are not a substitute for face-to-face learning. In the constructivist approach, the image of a teacher as a "sage on the stage" is dispensed with in favor of a learning facilitator more commonly known as a "guide on the side". Taken too far, the constructivist paradigm can, however, become as inflexible as the instructional approach its proponents are eager to dismantle [Baines 2000].

\subsection{Overcoming the barriers}

An essential part of the planning process for the new undergraduate curriculum in optical science and engineering will be an identification of the obstacles to its implementation and a design of strategies to overcome these barriers.

Calls for a reform of undergraduate engineering education are not new. Yet, most teaching faculty at UNM have not bothered to seriously consider and embrace them. Part of the proposed planning process will be to conduct surveys that will help to identify and understand barriers to instructional change at UNM. These surveys will be prepared and evaluated by the College of Education participants.

Some of the existing barriers may be subjective, such as the powerful influence of educational tradition, faculty self-perceptions and self-definition of roles, the discomfort and anxiety that change creates, the limited incentives for faculty to change, and the perception of a high risk associated with the employment of active learning. There are perceived risks that students may not wish to participate, may not be able to use higher-order thinking, or learn sufficient content, that instructors will feel a loss of control, lack necessary skills, or be criticized for teaching in unorthodox ways. Other factors may be more objective, for example limited class time; a possible increase in preparation time; the potential difficulty of using active learning in large classes; and a lack of needed materials, equipment, or resources. While faculty workshops may address the subjective domain, the objective obstacles need to be clearly identified, and plans for their removal in the implementation stage will be formulated. This process is especially important since system and infrastructure upgrades would likely be required to adopt the curricular reform.

As part of our strategy towards overcoming the barriers, we intend to fully utilize the resources available through the NSF-funded Engineering Education Coalitions, focusing on faculty workshops led by invited Coalition 
instructors as a way of improving the teaching effectiveness of the optics faculty. In particular, we plan to hold a series of monthly workshops on:

- Teaching Effectiveness (Student-Centered Approach to Teaching; Effective Teaching with Technology; Active/Cooperative Learning: Introduction and Applications; Active/Cooperative Learning: After the Basics; Student Teams in Engineering: Introduction and Applications);

- Curriculum Development (Freshman Engineering Programs; Interdisciplinary Freshman Engineering Design; Curriculum Integration: Why and How; Multidisciplinary Design);

- Student Success and Development (Retention of Undergraduate Students in Engineering; Bridge Programs: The STEPUP Approach; Peer Mentoring: The MAPS Approach); and

- Assessment (Planning the Assessment of Engineering Education Research; Developing Measurable Objectives and Outcomes for Programs and Courses).

These workshops will also be open to other engineering faculty, as the techniques involved are clearly of general interest and can be utilized in other engineering disciplines. Of critical importance is participation of nonengineering faculty who teach elective courses that engineering students take.

\subsection{Outcome assessment, evaluation, and feedback}

The planning process and especially the subsequent implementation of the new B.S. in Optical Science and Engineering degree will provide a fertile ground for identifying and pursuing instructional and cognitive science research problems. This will not only assist in overcoming initial barriers, but will also help to guide future practices in the classroom and to develop approaches tailored to the unique population mix of New Mexico. In particular, we envisage rigorous studies on effectiveness of active and cooperative learning strategies that will explore the impact of important student characteristics, such as their ethnic background, gender, learning styles, and stage of intellectual development. Among other factors, we plan to examine in the implementation stage the differences in performance and attitudes between students from different ethnic groups (with emphasis on Native American and Hispanic students), from different community backgrounds (rural, small town, suburban, and urban), different family backgrounds (level and type of education of parents), and between male and female students. Background information on the studied cohort will be recorded, including demographic data, SAT and AP scores, grade-point averages and grades in selected freshman and subsequent courses, and scores on both the Myers-Briggs Type Indicator ${ }^{\circledR}$ (MBTI), a personality inventory based on Jung's theory of psychological types, the Learning and Study Strategies Inventory ${ }^{\circledR}$ (LASSI), an instrument that assesses students' test-taking skills and strategies, motivation to learn, and anxiety levels, and the Motivated Strategies for Learning Questionnaire (MSLQ) derived from a program of research at the University of Michigan led by Paul Pintrich which has Motivational Scales and Learning Strategies Scales. The data will also include statistics on persistence in the optical science and engineering curriculum, and students' self-evaluations and reactions to their educational experiences. A comparison group will consist of students taking the traditional EE and P\&A curricula, as well as optical science and engineering students taking traditional lecture courses. The results of this research will be disseminated in journals widely read by both education and engineering faculty.

Tom Angelo, the director of the American Association for Higher Education (AAHE) Assessment Forum, formulated the following useful definition of assessment [Angelo 1995]: Assessment is the ongoing process aimed at understanding and improving student learning. It involves making our expectations explicit and public; setting appropriate criteria and high standards for learning quality; systematically gathering, analyzing and interpreting evidence to determine how well performance matches those expectations and standards; and then using the resulting information to document, explain, and improve performance.

Active learning itself can be used as an effective assessment tool. Most post-secondary faculty are familiar only with summative assessment, i.e., a formal assessment in which student performance is assigned a grade that denotes a specific level of proficiency or achievement. Summative assessment typically translates into one or two major tests and a final. In recent years, however, the concept of assessment has been broadened to include formative classroom assessment, which comprises informal assessment techniques designed primarily to improve teaching and learning in a more systematic fashion [Angelo 1993]. This ungraded assessment, coupled with active learning, can be a powerful tool for transforming a passive classroom into one filled with active participants. For example, it can be used in conjunction with mini-lectures to verify whether students understand a key point or concept. Using a thinkpair-share approach [Bonwell 1997] can be particularly effective to stimulate classroom discussion on a subject.

Most traditional classroom tests focus on the assessment of knowledge. Skill development has been usually perceived as something that should be done outside the classroom - in the laboratory, by solving homework problems, by writing papers, etc. Experience suggests, however, that students need explicit coaching on developing 
skills inside the classroom prior to extending those skills outside the classroom. For example, to develop problemsolving skills, students can be asked to work out problems illustrative of the day's material. Such exercises allow students to develop skill proficiency in a safe environment and allow instructors to determine areas that need further explication. In this way, skill assessment can be combined with an enhanced effectiveness of instruction.

\subsection{Development of new instructional materials}

An important outcome of the strong interaction between the optics and education faculty and graduate students will be a series of new textbooks created in the process of development and implementation of the new program. In the past, standard textbooks have focused on a presentation of technical content accompanied by problems to be solved by students at home. Solution manuals and computer software were the only additional materials the instructors could expect to have. We envisage a novel model for creation of modern textbooks written jointly by the faculty teaching optical science and engineering courses and the experts from the College of Education who will assist in preparing unique instructional aids. These additional materials will focus on specific approaches teachers can take to introduce active/cooperative learning in their classrooms, and will contain examples of formative tests which could be used during the instruction, all in the specific context of a particular textbook. This approach will ensure the widest possible dissemination and transfer of the new knowledge acquired by the UNM faculty to other universities and colleges, and will contribute significantly to a wider use of effective teaching styles.

The new instructional aid materials will utilize the concept of abilities-based education [Bonwell 1997], with three essential components of ability: knowledge, skills, and attitudes. Evaluation criteria to be communicated to students prior to administration of the tests will also be listed. These evaluation criteria will be developed empirically in UNM classrooms using active participation by the students. Recommendations will also be included on how to train students to take part in a formative assessment of their colleagues.

\section{Integrating diversity into the new program}

The University of New Mexico (UNM) operates as a Carnegie Doctoral/Research University - Extensive and as a recognized Hispanic-Serving Minority Institution. The University holds a dual commitment to excellence in research and to education opportunities for minorities. It has over 30,000 students, including over 5,000 graduate students. UNM continues to strive for new levels of excellence in its teaching, research, and service, and believes that a key factor for reaching these goals lies in support for and participation from its diverse student body. UNM has a large percentage (37.5\% of main campus enrollment) of minority students, especially at the undergraduate level.

According to the rankings published in the May 6, 2002 issue of Hispanic Outlook in Higher Education, UNM is ranked 15th on the list for conferring bachelor's degrees to Hispanics, 22nd for master's degrees, and 14th for Ph.D.'s. Of the 2,723 bachelor's degrees conferred in 2000, Hispanics earned 706 (25.9\%); for master's, 976 degrees were conferred, 145 of them were earned by Hispanics (14.9\%); for Ph.D.'s, UNM awarded 184 with 17 going to Hispanics (9.2\%). On Hispanic Outlook's list of Carnegie-classified institutions by Hispanic enrollment, UNM ranks $6^{\text {th }}$ in overall classification with 6,579 Hispanic students, and $1^{\text {st }}$ among the Carnegie Research I institutions. The School of Engineering, ranked in 2002 as \#40 in the US News and World Report Top 50 Engineering Schools in the $U S$, attracts top quality minority students that provide a valuable pool of talent capable of conducting world-class research.

UNM benefits from diverse demographics of the state, with a $42.1 \%$ Hispanic and $8.9 \%$ Native American population base (Census 2000 data). Efforts will be made to recruit and retain in the new program high percentages of underrepresented minority students, women, and students with disabilities.

In this context, it is particularly important to include branch campuses and remote sites. For example, the lower division class at the UNM Gallup Branch is $65 \%$ Navajo and 10\% Zuni Pueblo, so that $75 \%$ of the student body is Native American. Additionally, the Gallup Branch has approximately 13\% Hispanic students, so that the Gallup campus is $88 \%$ minority serving. The Upper Division Teacher Education Certification \& Bachelor's Degree program graduates more Navajos than any other ethnic group. With additional outreach at the Diné College and UNM lower division programs, the Gallup Branch serves an overwhelming percentage of Native American and Hispanic students from New Mexico. These traditionally underserved populations could catalyze a solution to the employment crisis in New Mexico, especially since these same populations are very stable and have lived here for hundreds of years.

We will work closely with Diné College campuses at Crownpoint, Shiprock and Tsaile, AZ as well as the UNM Branch campuses at Gallup, Los Alamos, and Taos to serve as feeder programs to the main campus program. Cohort groups will be identified and counseled into training for the main campus program from all of these two-year, junior-college programs as well as from the lower division of the UNM main campus. 
There are a large number of existing programs in New Mexico that assist students from historically underrepresented ethnic groups to prepare for and succeed in college education. For example, New Mexico MESA (Mathematics, Engineering, Science Achievement), Inc., operating on an annual budget of $\sim \$ 1.6$ million, prepares pre-college students for college majors and careers in mathematics, engineering, science, and related fields. During the year 2000/2001, 4,686 students were served (almost double the number of students served 10 years earlier), of which 1,667 (35.6\%) were female Hispanics, 1,201 (25.6\%) were male Hispanics, 273 (5.8\%) were female Native Americans, and 207 (4.4\%) were male Native Americans. We will be working closely with these programs to make them aware of the career opportunities in optics and photonics.

Among the mechanisms to increase the number of minority students electing to pursue the optical science and engineering degree, we envisage summer internships for high-school students from small-town and rural areas of New Mexico and for lower-division students attending UNM branch campuses. During those internships, the students will participate in various optics- and photonics-related research projects under the supervision of graduate students.

\subsection{Coordination with community colleges}

The new degree program requires further study in order to develop effective articulation between the Associate Degree programs at New Mexico's community colleges and those entering with advanced placement in a baccalaureate degree program. For example, the level of math proficiency may need to be bolstered to enable the ATVI students who are articulating with UNM to move smoothly into the calculus-based science and mathematics courses required at UNM.

Programs of study in basic optics are already available at the Crownpoint Institute of Technology and Southwestern Polytechnic Institute, and would require the addition of a few classes to complete their Associates Degree level program.

\subsection{Improvement of engineering content in $\mathrm{K}-12$ education}

UNM will work together with Sandia National Laboratories and Albuquerque Public Schools to further expand outreach programs, beyond the Photonics Academy at West Mesa High School (see Fig. 1). For example, photonics will be included in the program of Advanced Technology Academy at the Albuquerque High School. Further efforts aimed at enriching the engineering content of K-12 education will be coordinated jointly by UNM, ATVI, and Albuquerque Public Schools (APS), in collaboration with Sandia National Laboratories.

It is expected that close collaboration between the optics and education faculty will result in development of approaches that encourage current and future teachers to use stimulating problems based on optical science and engineering that illustrate real-world applications of mathematics and science. Such real-world examples are expected to increase the level of pre-college student interest and motivation, leading to an increased enrollment in engineering degree programs in general, and in the new B.S. in Optical Science and Engineering program in particular.

\subsection{Teacher education}

An essential part of improved engineering content in K-12 education is teacher preparation. Currently, there is a vast shortage of teachers and laboratory professional to serve the emerging needs of New Mexico's schools and national laboratories. The new program will create new opportunities for increased interactions between engineering and education students and faculty, with the goal of enhancing the engineering and engineering technology content of the programs of study of pre-service teachers and general education majors, as well as developing new strategies for improved pedagogy and evaluation in undergraduate engineering and engineering technology.

There are presently little to no interactions between engineering and education in teacher licensure programs. An important direction that will be pursued by the participating College of Education faculty is preparation of a course for educators on the aspects of engineering in the K-12 setting.

\subsection{Optics and Photonics Education Summit and a follow-on workshop}

The unique optics and photonics educational environment illustrated in Fig. 1 can and should be expanded to include more K-12 schools, more community colleges, and more university campuses. We are organizing an Optics and Photonics Education Summit that will be devoted to further strengthening of optics and photonics education in New Mexico at all levels of the educational ladder (cf. Fig. 1). 
In a small-and-diverse-population, large-area state such as New Mexico, collaboration, cooperation, and communication are of extreme importance to maximize the benefit from the planners and efforts of community drivers. New Mexico has selected optics and photonics to be one of its prime future economic drivers, without negative effects upon its cherished and unique character. The Summit will allow for identifying and leveraging meaningful resources, while calling attention to this emerging field. According to NSF, New Mexico ranks near, if not at the top of the nation in the ratio of R\&D expenditures to gross state product - which means to many that technology for all the right reasons is more important to the well being of this state than any other. An Education Summit bringing the educational and political leaders together will help ensure and strengthen our continued technical enterprise leadership, as well as demonstrating to others our unique approach to educational requirements of an emerging-technology-based economy, especially as it applies to workforce development.

Based on the educational as well as socioeconomic issues identified at the Summit, we plan to organize a smaller, more focused follow-on workshop at UNM, concentrating on the new B.S. program. The main purpose of this workshop will be to develop actual strategies and tactics to fold in the entire range of such mostly external, often highly interdependent factors into a viable plan for the new degree program.

Our experience with the recently approved M.S. degree in Optical Science and Engineering has confirmed the efficacy of a consensus-building approach in the larger community of optics professionals throughout the State. The two-step approach we propose here, of holding a broad exploratory educational summit followed by a more dedicated and focused workshop, will not only achieve such consensus, but also lead to the development of a concrete degree proposal.

\section{ABET accreditation}

An important goal of the proposed program will be to achieve the accreditation status from the Accreditation Board for Engineering and Technology, Inc. (ABET). Presently, only one program related to optics has ABET accreditation, namely B.S. in Optical Engineering at the University of Alabama at Huntsville, focusing on conventional optical system design. University of Pennsylvania offers an Electronic and Photonic Materials Option as part of their accredited B.S. in Materials Science and Engineering degree program. Thus, the proposed program will be the first accredited Optical Science and Engineering degree program in the nation.

In order to assure future accreditation, all of the evaluation criteria adopted by ABET in their accreditation process will be incorporated in the proposed program.

\section{Conclusions}

The new program could not be more timely for New Mexico. It will bridge the last remaining gap in the unique hierarchy of photonics educational programs in New Mexico, starting with the Photonics Academy at West Mesa High School supported by Sandia National Laboratories that feeds into the Photonics Technology Associate Degree program at the Albuquerque Technical Vocational Institute, and culminating with the M.S. and Ph.D. programs in Optical Science and Engineering offered at UNM. The comprehensive line-up of educational and career options in optics and photonics that would be enabled by the new B.S. degree will permit New Mexico industry to fill its photonics-centered positions at all levels, from the technician to the advanced researcher, from a workforce trained locally. The new degree will, more generally, help meet the emerging workforce and educational needs of the entire US industry.

\section{Acknowledgements}

This paper describes a planning grant supported by the National Sciences Foundation under the Bridges for Engineering Education program, award \#EEC-0230150, cognizant program officer Sue Kemnitzer.

\section{References}

[Angelo 1993] T. A. Angelo and P. C. Cross, Classroom Assessment Techniques, $2^{\text {nd }}$ Ed., Jossey-Bass, San Francisco 1993.

[Angelo 1995] T. A. Angelo, "Reassessing (and defining) assessment: A second try", AAHE Bulletin 48, pp. 7-9, Nov. 1995.

[Astin 1993] A. W. Astin, What Matters in College: Four Critical Years Revisited, Jossey-Bass, San Francisco 1993. 
[Baines 2000] L. A. Baines and G. Stanley "We want to see the teacher", Phi Delta Kappan 82 (\#4), pp. 327-330, Dec. 2000.

[Besterfield-Sacre 1997] M. Besterfield-Sacre, C. J. Atman, and L. J. Shuman, "Characteristics of freshman engineering students: Models for determining student attrition in engineering”, J. Engineer. Educ. 86 (\#2), pp. 139-149, 1997.

[Bolles 1988] E. Bolles, Remembering and Forgetting: Inquiries Into the Nature of Memory, Walker \& Co., New York 1988.

[Bonwell 1991] C. C. Bonwell and J. A. Eison, "Active learning: Creating excitement in the classroom", $A S H E-$ ERIC Higher Education Report No. 1, 1991.

[Bonwell 1997] C. C. Bonwell, "Using active learning as assessment in the postsecondary classroom", Clearing House 71 (\#2), pp. 73-76, Nov./Dec. 1997.

[Bransford 1999] J. Bransford, A. Brown, and R. Cocking (Eds.), How People Learn: Brain, Mind, Experience, and School, National Academy Press, Wasington, DC, 1999.

[Burden 1998] P. R Burden and D. M. Byrd, Methods for Effective Teaching, $2^{\text {nd }}$ Ed., Allyn and Bacon, Boston 1998.

[Chickering 1987] A. Chickering and Z. Gamson, "Seven principles for good practice", AAHE Bulletin 39, pp. 3-7, March 1987.

[Collier 1980] K. G. Collier, "Peer-group learning in higher education: The development of higher-order skills", Stud. Higher Educ. 5, pp. 55-62, 1980.

[Craik 1972] F. I. M. Craik and R. Lockhart, "Levels of processing: A framework for memory research", J. Verbal Learn. Verbal Behav. 9, pp. 671-676, 1972.

[Felder 1998] R. M. Felder, G. N. Felder, and E. J. Dietz, “A longitudinal study of engineering student performance and retention. V. Comparisons with traditionally-taught students”, J. Engineer. Educ. 87 (\#4), pp. 469-480, 1998.

[Gage 1998] N. L. Gage and D. C. Berliner, Educational Psychology, $6^{\text {th }}$ Ed., Houghton Mifflin Co, Boston 1998.

[Hammen 1994] C. S. Hammen and J. L. Kelland, "Attendance and grades in a human physiology course", $A d v$. Physiol. Educ. 12, pp. S105-S108, 1994.

[Heckel 1996] R.W. Heckel, "Engineering freshman enrollments: Critical and non-critical factors", J. Engineer. Educ. 85 (\#1), pp. 15-21, 1996.

[Hyman 1980] R. T. Hyman, Improving Discussion Leadership, Columbia Univ., Teachers College Press, New York 1980.

[Jenkins 2002] S. R. Jenkins, J. B. Pocock, P. D. Zuraski, R. B. Meade, Z. W. Mitchell, and J. J. Farrington, "Capstone course in an integrated engineering curriculum", J. Professional Issues in Engineering Education and Practice 128 (\#2), pp. 75-82, April 2002.

[Johnson 1991] D. W. Johnson, R. T. Johnson, and K. Smith, Active Learning: Cooperation in the College Classroom, Interaction Book Company, Edina, MN, 1991.

[Jonassen 1993] D. H. Jonassen and B. L.Grabowski, Handbook of Individual Differences, Learning, and Instruction, Lawrence Erlbaum Associates, Hillsdale, NJ, 1993.

[King 1993] A. King, "From sage on the stage to guide on the side", College Teaching 411, pp. 30-35, 1993.

[Kvam 2000] P. H. Kvam, "The effect of active learning methods on student retention in engineering etatistics", American Statistician 54 (\#2), pp. 136-140, May 2000.

[Latane 2002] B. Latane, "Focused interactive learning: A tool for active class discussion”, Teaching of Psychology 29 (\#1), pp. 10-15, Feb. 2002.

[Lowman 1984] J. Lowman, Mastering the Techniques of Teaching, Jossey-Bass, San Francisco 1984.

[McKeachie 1986] W. J. McKeachie, P. R. Pintrich, Y.-G. Lin, and D. A. F. Smith, "Teaching and Learning in the College Classroom: A Review of the Research Literature", Univ. of Michigan Ann Arbor, 1986.

[McKeachie 1994] W. J. McKeachie, Teaching Tips: A Guidebook for the Beginning College Teacher, $9^{\text {th }}$ Ed., D.C. Heath, Lexington, MA 1994.

[Meyers 1993] C. Meyers and T. B. Jones, Promoting Active Learning: Strategies for the College Classroom, Jossey-Bass, San Francisco 1993.

[Moller-Wong 1997] C. Moller-Wong and A. Eide, "An engineering student retention study", J. Engineer. Educ. 86 (\#1), pp. 7-15, 1997.

[Navarra 2001] A. Navarra, D. Hull, A. Guenther, and L. S. Pedrotti, "Whence the technicians?", Photonics Spectra 35 (\#4), pp. 115-118, April 2001.

[Penner 1984] J. G. Penner, Why Many College Teachers Cannot Lecture, Charles C Thomas, Publisher, Springfield, IL 1984. 
[Poppenhagen 1982] B. W. Poppenhagen, E. M. Schuttenberg, and J. P. Gallagher, "Active learning for postsecondary educators: A study of two learning designs", Alternative Higher Educ. 61, pp. 242-257, 1982.

[Ruhl 1987] K. L. Ruhl, C. A. Hughes, and P. J. Schloss, "Using the pause procedure to enhance lecture recall", Teacher Educ. \& Special Educ. 10, pp. 14-18, Winter 1987.

[Stuart 1978] J. Stuart and R. J. D. Rutherford, "Medical student concentration during lectures", Lancet 2, pp. 514$516,1978$.

[Sutherland 1996] T. E. Sutherland and C. C. Bonwell (Eds.), Using Active Learning in College Classes. New Directions for Teaching and Learning, No. 67. Jossey-Bass, San Francisco 1996.

[Thielens 1987] W. Thielens, "The disciplines and undergraduate lecturing", Annual Meeting of American Educational Research Association, April 1987, Washington, DC.

[Wiggins 1998] G. Wiggins and J. McTighe, Understanding by Design, ASCD (Association for Supervision and Curriculum Development), Washington, DC, 1998, ISBN 0-87120-313-8. 